China Ocean Eng., 2021, Vol. 35, No. 1, P. 159

DOI: https://doi.org/10.1007/s13344-021-0029-9, ISSN 0890-5487

http://www.chinaoceanengin.cn/ E-mail: coe@nhri.cn

\title{
Retraction Note: Experimental Study on Crescent Waves Diffracted by A
}

Circular Cylinder [China Ocean Engineering, 2018, 32(5), 624-632. https://doi.org/10.1007/s13344-018-0064-3]

YAN Kai ${ }^{b}$, SHEN Liang-duo ${ }^{\text {a, b, * }}$, SHANG Jin-weib ${ }^{\text {, MA Liang }}{ }^{\mathrm{b}}$, ZOU Zhi-lib

a School of Port and Transportation Engineering, Zhejiang Ocean University, Zhoushan 316022, China

b State Key Laboratory of Coastal and Offshore Engineering, Dalian University of Technology, Dalian 116024, China

C2021 Chinese Ocean Engineering Society and Springer-Verlag GmbH Germany, part of Springer Nature

The authors have retracted this article (Yan et al., 2018) because it contains data without authorisation for use. All authors agree to this retraction.

\section{Reference}

Yan, K., Shen, L. D., Shang, J. W., Ma, L. and Zou, Z.L., 2018. Experimental study on crescent waves diffracted by a circular cylinder, China Ocean Engineering, 32(5), 624-632. 